\title{
$\alpha, \beta$-Methylene-ATP-Induced Inhibition of Acetylcholine Release on the Stellate Ganglion: Contribution of Nitric Oxide
}

\author{
Kazushi Kushiku ${ }^{*}$, Hiromi Yamada1, Nobufumi Ono ${ }^{2}$ \\ ${ }^{1}$ Department of Pharmacology, Faculty of Medicine, Fukuoka University, Fukuoka, Japan \\ ${ }^{2}$ Medical Informatics and Research Unit, Faculty of Pharmaceutical Sciences, Fukuoka University, Fukuoka, \\ Japan \\ Email: ${ }^{*}$ kkushiku@jcom.home.ne.jp
}

Received 8 August 2015; accepted 15 September 2015; published 18 September 2015

Copyright (C) 2015 by authors and Scientific Research Publishing Inc.

This work is licensed under the Creative Commons Attribution International License (CC BY). http://creativecommons.org/licenses/by/4.0/

(c) (7) Open Access

\begin{abstract}
In this study, we investigated the possible involvement of nitric oxide pathways in the presynaptic inhibition of acetylcholine release induced by ATP analogs in dogs. We performed the study using HPLC with electrochemical detection and the nitric oxide detection-HPLC system. The amount of acetylcholine released in response to preganglionic stimulation at $5 \mathrm{~Hz}$ for $10 \mathrm{~min}$ was reduced in a concentration-dependent manner after exposure to $10^{-7}-10^{-4} \mathrm{M} \alpha, \beta$-methylene-ATP $(\alpha, \beta$ meATP), but not by the P2Y receptor agonist, 2-methyl-thio-ATP (2MeSATP) or the P2X $\mathrm{X}_{1}$ receptor agonist, $\beta, \gamma$-methylene-ATP $(\beta, \gamma$-meATP), at the same concentrations. The inhibition of acetylcholine release induced by $\alpha, \beta$-meATP was antagonized by: the nonselective P2 receptor antagonist, pyridoxalphosphate-6-azophenyl-2',4'-disulphonic acid (PPADS); the $P 2 X_{1}, P_{2} X_{3}$ and $P 2 X_{2 / 3}$ receptors antagonist, 2'-(or-3')-0-trinitrophenyl-ATP (TNP-ATP); the neuronal nitric oxide synthase (nNOS) inhibitor, 3-bromo-7-nitroindazole; the soluble guanylyl cyclase inhibitor, $1 \mathrm{H}-[1,2,4]$ oxadiazolo[4,3-a]quinoxalin-1-one (ODQ); the NO scavenger, 2-(4-carboxyphenyl)-4,4,5,5-tetramethylimidazoline-1-oxyl-3-oxide (carboxy-PTIO). Exposure to $10^{-5} \mathrm{M}$, but not $10^{-4} \mathrm{M}, \alpha, \beta$-meATP, for 30 min increased the levels of $\mathrm{NO}_{x}^{-}$, and this increase was antagonized by TNP-ATP and 3-bromo7-nitroindazole. These results show that $\mathrm{P} 2 \mathrm{X}$ receptor activation inhibits stellate ganglionic transmission by reducing acetylcholine release from presynaptic nerve terminals and that this inhibition seems to involve, at least in part, the activation of endogenous NO production and cGMP pathways.
\end{abstract}

\section{Keywords}

$\alpha, \beta$-meATP, Acetylcholine, Nitric Oxide, Stellate Ganglion, Synaptic Modulation

\footnotetext{
${ }^{*}$ Corresponding author.
}

How to cite this paper: Kushiku, K., Yamada, H. and Ono, N. (2015) $\alpha$,6-Methylene-ATP-Induced Inhibition of Acetylcholine Release on the Stellate Ganglion: Contribution of Nitric Oxide. Neuroscience \& Medicine, 6, 134-147. 


\section{Introduction}

A role for ATP in autonomic ganglia was first reported in 1948 when Feldberg and Hebb demonstrated that the intra-arterial injection of ATP in cats excited neurons in the superior cervical ganglia [1]. Later, work from de Groat's laboratory showed that purines inhibited synaptic transmission through adenosine receptors in cat vesical parasympathetic ganglia and rat superior cervical ganglia, but that high concentrations of ATP depolarized and excited the postganglionic neurons [2].

The rat superior cervical ganglion contains $\mathrm{P} 2 \mathrm{X}$ receptors that are activated by ATP or a selective $\mathrm{P} 2 \mathrm{X}$ receptor agonist, $\alpha, \beta$-methylene-ATP $(\alpha, \beta$-meATP), which depolarizes these neurons [3]. A reduction of the amount of acetylcholine released from preganglionic nerve terminals by ATP may result from a decrease in $\mathrm{Ca}^{2+}$ influx, due mainly to a depolarization of the preganglionic nerve terminals [4]. P2X receptors are important for synaptic transmission in enteric ganglia, although their roles in sympathetic and parasympathetic ganglia are less clear [5].

There is increasing evidence that ATP plays a role in neurotransmission in mammalian autonomic ganglia [2] [6]. The pharmacological effects of ATP in neurons have been studied in many ganglia, including the dorsal root ganglion [7] [8], the nodose ganglion [9], the superior cervical ganglion [10] [11], and the celiac ganglion [12] [13]. In the guinea pig, $\alpha, \beta$-meATP is an effective agonist of superior cervical ganglia [11] [14] and celiac ganglion neurons [9]. In contrast, $\alpha, \beta$-meATP evoked only small and slowly desensitizing responses in a subpopulation of neurons from the rat superior cervical ganglion [9] [15]. In a study of rat and mouse celiac ganglion neurons, no response to $\alpha, \beta$-meATP was detected [16]. Based on these data, Burnstock has shown that there is a species difference between rat and guinea pig [2]. While the responses to purines in the autonomic ganglionic transmission of many species have been investigated, there are few reports describing the actions of purines on sympathetic ganglionic transmission in canines.

Studies describing the effects of ATP analogs on the direct and chemical determination of classical neurotransmitter release in the sympathetic ganglia are insufficient to characterize the specific biochemical/receptor mechanisms of ganglionic transmission in canines. According to past research [17]-[20], the isolated canine stellate ganglion serves as a convenient and readily accessible model that can contribute to our understanding of cholinergic transmission. Thus, in the current study, we investigated the presynaptic effects of ATP analogs on ganglionic transmission by directly measuring acetylcholine release caused by preganglionic electrical stimulation in order to determine the possible biochemical/receptor mechanisms involved.

Our interest in exploring the specific role of nitric oxide (NO) in ganglionic transmission stems from the fact that it has been shown to play an important role in the control of synaptic function in both the peripheral and central nervous systems [21]. NO is synthesized in neurons by the activation of NO synthase (NOS) in a Ca ${ }^{2+}-$ calmodulin-dependent manner, in the presence of l-arginine as substrate, tetrahydrobiopterin, and nicotinamide adenine dinucleotide phosphate (NADPH) [22]. NOS is found in the majority of preganglionic cholinergic neurons of the sympathetic nervous system in rats [23] [24], guinea pigs [25], cats [26] [27], mice, and monkeys [26]. The histochemical results have shown that ATP and NO coexist in a subpopulation of ganglionic neurons in the ileum, proximal colon, and anococcygeus muscle of rat [28]. Previously, we demonstrated that the neuropeptide endothelin inhibited sympathetic ganglionic transmission at presynaptic sites via the endothelin-B receptor by reducing acetylcholine release through the stimulation of NO production and the cGMP pathways [20].

The aim of this study was to investigate the effects of purinergic signaling on the presynaptic release of acetylcholine and its effects on canine sympathetic ganglionic transmission.

\section{Materials and Methods}

\subsection{Animals}

Adult mixed-breed dogs of both sexes, provided by the Fukuoka City Animal Control Center, were housed at the Fukuoka University Animal Center for about one week while they underwent a general medical examination. Each dog was housed in an individual cage in a room in which the temperature was maintained at $22^{\circ} \mathrm{C}$, humidity at $50 \%-60 \%$, and illumination was alternated on a 12-h light/dark cycle. All animals had free access to water and were fed $300 \mathrm{~g}$ standard solid laboratory diet (ED-1, Sanwa Chemicals Inc., Tokyo, Japan) per dog per day. Only animals in good physical health were used in the experiments. Experimental protocols were approved by the Animal Care Committee of Fukuoka University and were in accordance with the principles outlined in 
the NIH Guide for the Care and Use of Laboratory Animals.

\subsection{Drugs}

The drugs used were: $\alpha, \beta$-meATP, 2MeSATP, and $\beta, \gamma$-meATP (Sigma Chemicals, MO, U.S.A.), pyridoxalphoshate-6-azophenyl-2',4'-disulphonic acid (PPADS: RBI, MA, U.S.A.), 2',3'-O-(2,4,6-trinitrophenyl)-adenosine5'-triphosphate (TNP-ATP: Molecular Probes, OR, U.S.A.), 3-bromo-7-nitroindazole (Tocris Cookson Ltd., Bristol, UK), 1H-[1,2,4] oxadiazolo[4,3-a]quinoxalin-1-one (ODQ: Tocris Cookson Ltd., Bristol, UK), 2-(4carboxyphenyl)-4,4,5,5-tetramethylimidazoline-1-oxyl-3-oxide (carboxy-PTIO: Tocris Cookson Ltd., Bristol, UK).

\subsection{In Vitro Experiments on the Ganglia}

All dogs (6 - $12 \mathrm{~kg})$ were anesthetized with pentobarbital sodium $(30 \mathrm{mg} / \mathrm{kg}$, i.v. $)$. Each dog's trachea was cannulated, and artificial ventilation was maintained by a Harvard animal respirator (model 613, Millis, MA). Both stellate ganglia were removed - together with about $3 \mathrm{~cm}$ of the preganglionic sympathetic nerve- for the nerve stimulation experiments.

To perform the acetylcholine assays, we placed the ganglia tissue specimens in a dish containing Locke's solution in the presence of physostigmine $\left(10^{-6} \mathrm{M}\right)$ at room temperature; they were then gassed with a mixture of $95 \% \mathrm{O}_{2}$ and $5 \% \mathrm{CO}_{2}$, and the tissue sheath around the ganglia was carefully removed. The experimental procedures were principally performed according to the methods described by Ohjimi et al. [17]. The composition of the Locke's solution was (in $\mathrm{mM}$ ): $\mathrm{NaCl}, 136 ; \mathrm{KCl}, 5.6 ; \mathrm{CaCl}_{2}, 2.2 ; \mathrm{MgCl}_{2}, 1.2 ; \mathrm{NaH}_{2} \mathrm{PO}_{4}, 1.2 ; \mathrm{NaHCO}_{3}, 20.0$; and glucose, 11.0.

Individual ganglion cells were transferred to micro-test tubes containing $0.7 \mathrm{ml}$ of fresh medium (Locke's solution containing physostigmine, $10^{-6} \mathrm{M}$ ) at $37^{\circ} \mathrm{C}$, gassed with a mixture of $95 \% \mathrm{O}_{2}$ and $5 \% \mathrm{CO}_{2}$, and equilibrated for $60 \mathrm{~min}$. The preganglionic nerve was laid across a bipolar platinum electrode suspended just above the surface of the solution and stimulated by $60-\mathrm{V}$ square-wave pulses of 1 -msec duration at a frequency of $5 \mathrm{~Hz}$ for $10 \mathrm{~min}$ each; we used an electric stimulator (SEN-3201, Nihon Kohden) that delivered pulses via an isolation transformer (SS-2015m, Nihon Kohden). The interval between each successive preganglionic stimulation was $10 \mathrm{~min}$.

To measure NO, both sides of the stellate ganglia (without preganglionic nerves) were prepared under the same experimental conditions as those described above. The ganglion was put into a micro-test tube containing $0.5 \mathrm{ml}$ Locke's solution, without physostigmine, at $37^{\circ} \mathrm{C}$ and then was gassed with a mixture of $95 \% \mathrm{O}_{2}$ and $5 \%$ $\mathrm{CO}_{2}$. At the end of the experiment, the ganglion without its nerve trunk was weighed after the removal of any excess moisture by pressing the ganglion between filter paper.

Acetylcholine was measured by HPLC with electrochemical detection, as described by Eva et al. [29] and Potter et al. [30]. A standard mixture of acetylcholine, choline and isopropylhomocholine chloride, each at concentrations of $2 \times 10^{-6} \mathrm{M}$ was prepared daily from a stock solution of $2 \times 10^{-3} \mathrm{M}$ stored at $4^{\circ} \mathrm{C}$. Isopropylhomocholine chloride, $15 \mu \mathrm{l}$ of $2 \times 10^{-5} \mathrm{M}$, an internal standard, was added into $300 \mu \mathrm{l}$ of sample solution and filtered through a $0.22 \mu \mathrm{m}$ membrane filter (UFC30GVOO, Millipore, Tokyo, Japan). Aliquots of the standard and the filtered samples, $5 \mu \mathrm{l}$ and $10 \mu \mathrm{l}$, respectively, were injected into the HPLC system. The temperature of the enzyme column was maintained at about $33^{\circ} \mathrm{C}$ by a column heater (U-620, Sugai, and Tokyo, Japan). The mobile phase consisted of $0.1 \mathrm{M}$ disodium hydrogen phosphate, buffered to $\mathrm{pH} 8.0$ with phosphoric acid, containing 0.6 $\mathrm{mM}$ tetramethylammonium (TMA) and $1.2 \mathrm{mM}$ sodium 1-decanesulfonate. The buffer was prepared first and filtered through a $0.45 \mu \mathrm{m}$ membrane filter (Tokyo Roshi, Tokyo, Japan). TMA and sodium 1-decanesulfonate were added, and the solution was degassed by bubbling helium gas at a flow rate of $100 \mathrm{ml} / \mathrm{min}$ for $30 \mathrm{~min}$. The pumping rate of the mobile phase was $1.0 \mathrm{ml} / \mathrm{min}$.

\subsection{Acetylcholine Release}

In the experiments performed on the isolated ganglia, the acetylcholine released by untreated ganglia was collected during two 10-min periods by changing the incubation medium. A third aliquot of fresh incubation medium was introduced containing either the agonist ( $\alpha, \beta$-meATP, 2MeSATP, or $\beta, \gamma$-meATP), as described previously [17], or the antagonist (PPADS, TNP-ATP, 3-bromo-7-nitroindazole, ODQ, or carboxy-PTIO). Fresh 
medium containing the corresponding agents at the same concentration was introduced after the preincubation to remove the resting amount of acetylcholine released during the preincubation periods. Five to six samples were taken in the acetylcholine assay experiment.

To assess the acetylcholine-release effects of the agonist and antagonist drugs, tissues were exposed to agonists $(\alpha, \beta$-meATP, 2MeSATP, and $\beta, \gamma$-meATP) for $20 \mathrm{~min}$, according to the above procedure [17], and antagonists (PPADS, TNP-ATP, 3-bromo-7-nitroindazole, ODQ, and carboxy-PTIO) at the same concentrations, and these were incubated for $20 \mathrm{~min}$. Five or six samples were collected in each acetylcholine assay experiment.

The effects of these drugs on acetylcholine release were evaluated by measuring the acetylcholine released into a $0.7-\mathrm{ml}$ incubation medium during the $10-\mathrm{min}$ period of preganglionic stimulation. Acetylcholine was measured in a 10- $\mu \mathrm{l}$ aliquot of the sample solution by HPLC; the total acetylcholine released into $0.7 \mathrm{ml}$ was calculated, and these values were expressed as a percentage of the initial acetylcholine output elicited by the first preganglionic stimulation.

\subsection{Measurement of $\mathrm{NO}_{2}^{-}$and $\mathrm{NO}_{3}^{-}$Levels}

Isolated ganglia with their preganglionic trunk removed were incubated in tubes containing $0.5 \mathrm{ml}$ Locke's solution and oxygenated with $95 \% \mathrm{O}_{2}$ and $5 \% \mathrm{CO}_{2}$ at $37^{\circ} \mathrm{C}$ in a water bath. The output of $\mathrm{NO}$ was collected over 30 -min periods, separated by 20 -min intervals. The first three samples collected were from untreated ganglia and provided a baseline; thereafter, drugs were added and the fourth, fifth, and sixth experimental samples were collected. The left ganglia were used as controls, and the right ganglia were treated with antagonists. Fresh medium containing the same antagonists at the same concentration was used to replace samples removed for NO measurement. Tissues were exposed to agonists $(\alpha, \beta$-meATP) for $30 \mathrm{~min}$, and antagonists (TNP-ATP or 3-bromo7-nitroindazole) for $20 \mathrm{~min}$ as described previously [20].

Aliquots of the samples incubated with the drugs were immediately frozen in chilled acetone with dry ice; they were stored below $-40^{\circ} \mathrm{C}$ until they were used in the assays. The NO metabolite content of the $0.5-\mathrm{ml}$ samples from the 30-min incubations with ganglia were calculated from the values measured in 20- $\mu$ aliquots using a NO detector-HPLC system (ENO-20, Eicom, Kyoto, Japan). The values were expressed as a percentage of the NO metabolite output of untreated ganglia during a 30-min incubation.

To measure $\mathrm{NO}_{2}^{-}$and $\mathrm{NO}_{3}^{-}$in the incubation medium, they were separated using a reverse-phase separation column packed with polystyrene polymer (NO-PAK, $4.6 \times 50 \mathrm{~mm}$, Eicom), and $\mathrm{NO}_{3}^{-}$was reduced to $\mathrm{NO}_{2}^{-}$using a reduction column packed with copper-plated cadmium filings (NO-RED, Eicom). Samples containing $\mathrm{NO}_{2}^{-}$were mixed with Griess reagent in a reaction coil to form a purple azo dye. The separation and reduction columns and the reaction coil were placed in a column oven at $35^{\circ} \mathrm{C}$. The dye produced was measured at an absorbance of $540 \mathrm{~nm}$ using a flow-through spectrophotometer (NOD-10, Eicom). The mobile phase (Eicom) consisted of $10 \%$ methanol in $0.15 \mathrm{M} \mathrm{NaCl}-\mathrm{NH}_{4} \mathrm{Cl}$ and $0.5 \mathrm{~g} / 1$ of EDTA-4Na, and it was pumped at a rate of $0.33 \mathrm{ml} / \mathrm{min}$. The Griess reagent (Eicom) was $1.25 \% \mathrm{HCl}$ containing $5 \mathrm{~g} / 1$ sulfanilamide with $0.25 \mathrm{~g} / 1 \mathrm{~N}-$ naphthyle-thylenediamine and was delivered at a rate of $0.1 \mathrm{ml} / \mathrm{min}$. The background levels of $\mathrm{NO}_{2}^{-}$and $\mathrm{NO}_{3}^{-}$ in Locke's solution were subtracted from the sample values in each experiment. The total NO metabolite levels $\left(\mathrm{NO}_{x}^{-}\right)$were calculated as the sum of the $\mathrm{NO}_{2}^{-}$and $\mathrm{NO}_{3}^{-}$levels.

\subsection{Statistical Analysis}

All values represent mean \pm standard error of mean. The differences between more than two mean values of the dose-response effects in the same ganglia were evaluated using Dunnett's test. Comparisons between left control ganglia and right experimental ganglia from the same animal were made using analyses of variance (ANOVA), followed by the Bonferroni $t$ test. Differences were considered significant at $\mathrm{p}$ values $<0.05$.

\section{Results}

\subsection{Effects of ATP Agonists on Acetylcholine Release}

Acetylcholine release in response to preganglionic nerve stimulation is frequency-dependent, increasing to $50 \%$ of the maximum at $5 \mathrm{~Hz}$ and reaching a maximum at $20 \mathrm{~Hz}$ [17]. Based on this, we stimulated the preganglionic nerve at a frequency of $5 \mathrm{~Hz}$ in these experiments. As shown in Figure 1, the output of acetylcholine induced by 


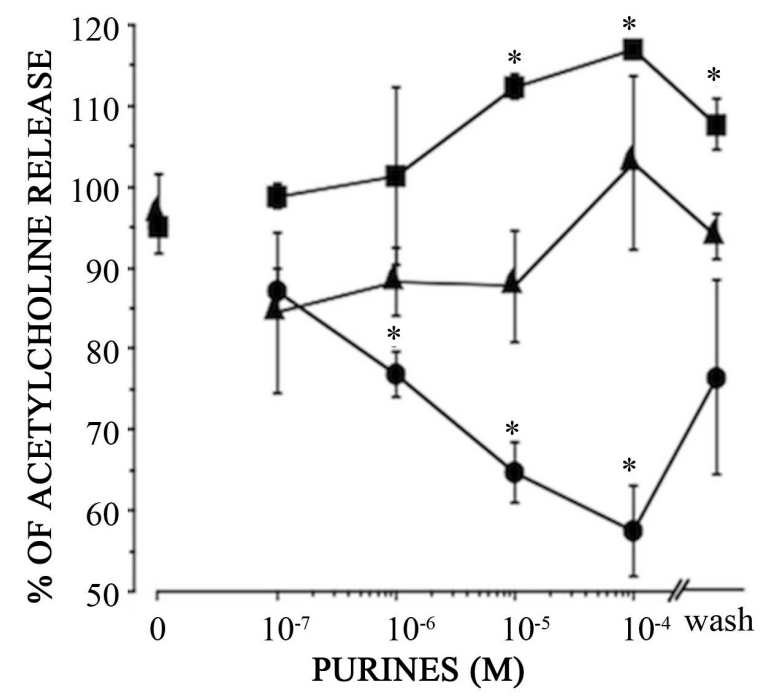

\begin{abstract}
Figure 1. Dose-response curves showing the inhibition of acetylcholine output elicited by preganglionic stimulation of ganglia by the ATP analogs: $\alpha, \beta$-methylene-P $(-\bullet-)$, 2-methyl-thio-ATP $\left(-\boldsymbol{\Delta}^{-}\right)$and $\beta, \gamma$-methylene-ATP $\left(-\boldsymbol{-}^{-}\right)$. The mean basal amount of acetylcholine released by preganglionic stimulation without agonist treatment were $7.1 \pm 0.52,4.8 \pm 0.57$ and $5.9 \pm 0.75 \mathrm{nmol} / 10 \mathrm{~min} / \mathrm{g}$. Each point represents the mean of 5 ganglia, and vertical bars represent SEMs. *significant difference between the values before and after agonists addition in the same ganglion $(\mathrm{p}<0.05)$.
\end{abstract}

preganglionic stimulation in each 10-min period was reduced in a dose-dependent manner in the presence of $\alpha, \beta$-meATP at concentrations of $10^{-6}$ to $10^{-4} \mathrm{M}$, with the output reduced to $57.4 \%$ of control at the maximum concentrations of $10^{-4} \mathrm{M}$. In contrast, acetylcholine release was not inhibited in the presence of the same concentrations of 2MeSATP or $\beta, \gamma$-meATP. In fact, the increased acetylcholine release induced by preganglionic stimulation was significantly augmented, rather than inhibited by $\beta, \gamma$-meATP at concentrations of $10^{-5}$ and $10^{-4}$ M. When these purine analogs were washed out, the level of acetylcholine output induced by preganglionic stimulation returned to near control levels (Figure 1).

\title{
3.2. Effects of the Nonselective $P 2$ Receptor Antagonist, PPADS, and the P2X $X_{1}$ and $P 2 X_{3}$ Receptor Antagonist, TNP-ATP, on the $\alpha, \beta$-meATP-Induced Reduction in Acetylcholine Release
}

As shown in Figure 2 and Figure 3, the $\alpha, \beta$-meATP-induced inhibition of acetylcholine release during preganglionic stellate stimulation was antagonized by incubation with $10^{-5} \mathrm{M}$ PPADS or TNP-ATP. Incubation with PPADS or TNP-ATP alone in the absence of $\alpha, \beta$-meATP did not affect acetylcholine release significantly (Figure 2 and Figure 3).

The inhibitory effect of ATP on nerve-evoked transmitter release is antagonized by bath application of PPADS at a dose of $10^{-5} \mathrm{M}[31] . \alpha, \beta$-meATP-evoked depolarization in rat superior cervical ganglia is also depressed by incubation with $10^{-5}-10^{-4} \mathrm{M}$ PPADS [32].

\subsection{Effects of nNOS Inhibitor, 3-Bromo-7-Nitroindazole, on $\alpha, \beta$-meATP-Induced Reduction of Acetylcholine Release}

As shown in Figure 4, the $\alpha, \beta$-meATP-induced inhibition of acetylcholine release during preganglionic stellate stimulation was antagonized by incubation with $10^{-5} \mathrm{M}$ 3-bromo-7-nitroindazole. The application of 3-bromo-7nitroindazole alone in the absence of $\alpha, \beta$-meATP tended to increase acetylcholine release, though not significantly (Figure 4). In a previous canine study [20], incubation with the same concentration of 3-bromo-7-nitroindazole did not significantly affect acetylcholine output elicited by preganglionic stimulation conducted in the same experimental manner. 


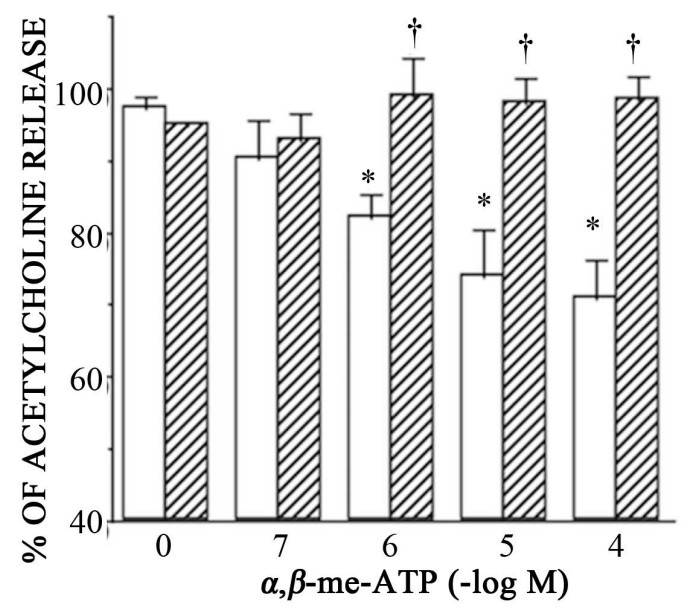

Figure 2. Effect of the nonselective P2 receptor antagonist, PPADS, on the $\alpha, \beta$-methylene-ATP-induced reduction in acetylcholine output elicited by preganglionic stimulation in untreated $(\square)$ and $10^{-5}$ M PPADS-treated ( $\mathbb{Z}$ ) ganglia. In two groups of ganglia, the mean basal amount of acetylcholine released by preganglionic stimulation before drug addition were $5.4 \pm 2.06$ and $5.8 \pm 2.27 \mathrm{nmol} / 10 \mathrm{~min} / \mathrm{g}$. Each column represents mean of 5 ganglia and vertical bars represent SEMs. *significant difference between values before and after $\alpha, \beta$-methylene-ATP addition in the same ganglion ( $\mathrm{p}$ $<0.05)$. † significant difference between untreated and PPADS-treated ganglia $(\mathrm{p}<$ $0.05)$. Each column represents the mean of 5 ganglia.

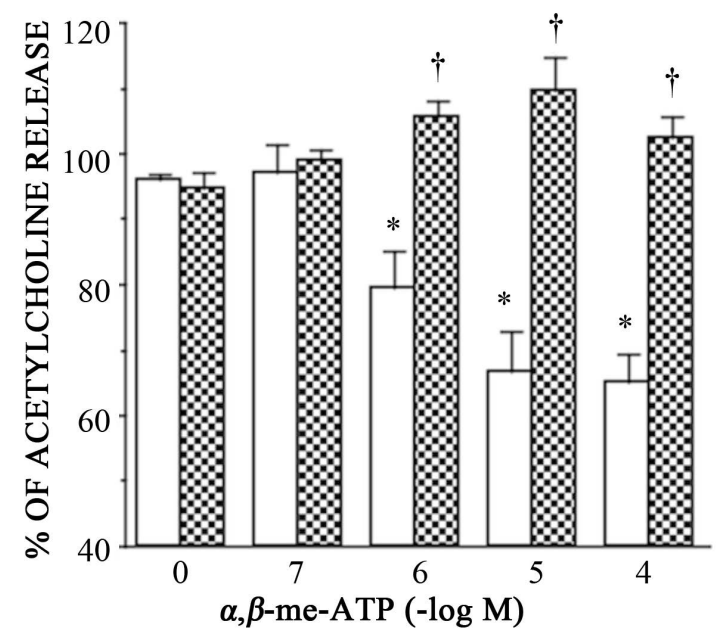

Figure 3. Effect of the $\mathrm{P}_{2} \mathrm{X}_{1}$ and $\mathrm{P} 2 \mathrm{X}_{3}$ receptor antagonist, TNP-ATP, on the $\alpha, \beta$ methylene-ATP-induced reduction in the acetylcholine output elicited by preganglionic stimulation in untreated $(\square)$ and $10^{-7} \mathrm{M}$ TNP-ATP-treated ( $\mathbf{D}$ ) ganglia. In two groups of ganglia, the mean basal amount of acetylcholine released by preganglionic stimulation before drug addition were $4.6 \pm 0.74$ and $5.7 \pm 1.88 \mathrm{nmol} / 10 \mathrm{~min} / \mathrm{g}$. *significant difference between the values before and after $\alpha, \beta$-methylene-ATP addition in the same ganglion $(\mathrm{p}<0.05)$. † significant difference between untreated and TNP-ATP-treated ganglia $(\mathrm{p}<0.05)$. Each column represents the mean of 5 ganglia. See the legends to Figure 2 for additional explanation.

\subsection{Effects of Soluble Guanylyl Cyclase Inhibitor, ODQ, on $\alpha, \beta$-meATP-Induced Reduction of Acetylcholine Release}

As shown in Figure 5, the reduction of acetylcholine output induced by $\alpha, \beta$-meATP at concentrations of $10^{-7}-10^{-4}$ 


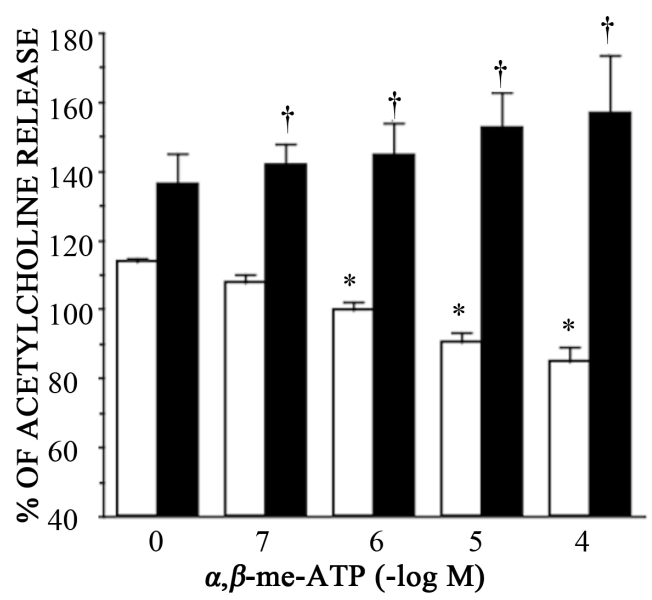

Figure 4. Effect of the nNOS inhibitor, 3-bromo-7-nitroindazole, on the $\alpha, \beta$-methylene-ATP-induced reduction in acetylcholine output elicited by preganglionic stimulation in untreated $(\square)$ and $10^{-5}$ M 3-bromo-7-nitroindazole-treated ( $\square$ ) ganglia. In two groups of ganglia, the mean basal amount of acetylcholine released by preganglionic stimulation before drug were $6.5 \pm 0.79$ and $6.2 \pm 0.62 \mathrm{nmol} / 10 \mathrm{~min} / \mathrm{g}$. * significant difference between the values before and after $\alpha, \beta$-methylene-ATP in the same ganglion $(\mathrm{p}<0.05)$. † significant difference between untreated and 3-bromo-7nitroindazole-treated ganglia $(\mathrm{p}<0.05)$. Each column represents the mean of 5 ganglia. See the legends to Figure 2 for additional explanation.

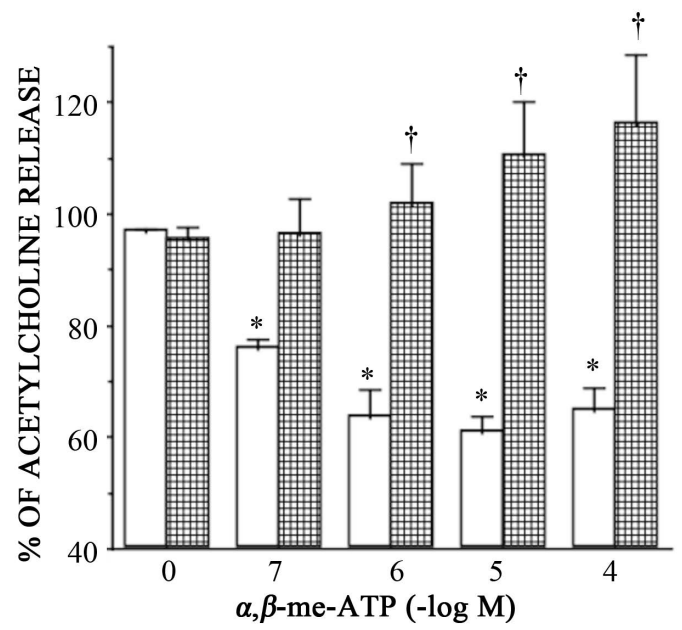

Figure 5. Effect of the soluble guanylyl cyclase inhibitor, ODQ, on the $\alpha, \beta$-methylene-ATP-induced reduction in acetylcholine output elicited by preganglionic stimulation in untreated $(\square)$ and $10^{-5} \mathrm{M}$ ODQ-treated (無) ganglia. In two groups of ganglia, the mean basal amounts of acetylcholine released by preganglionic stimulation before drug addition were $6.5 \pm 0.79$ and $6.2 \pm 0.62 \mathrm{nmol} / 10 \mathrm{~min} / \mathrm{g}$. * significant difference between the values before and after $\alpha, \beta$-methylene-ATP addition in the same ganglion $(\mathrm{p}<0.05)$. †significant difference between untreated and ODQ-treated ganglia $(\mathrm{p}<$ 0.05 ). Each column represents the mean of 5 ganglia. See the legends to Figure 2 for additional explanation.

$\mathrm{M}$ was antagonized by incubation with the soluble guanylyl cyclase inhibitor, ODQ, at $10^{-5} \mathrm{M}$. ODQ alone, at the same concentration did not affect acetylcholine release elicited by preganglionic stimulation (Figure 5). Similarly, Yamada et al. [20] had found that ODQ, even at the relatively high concentration of $10^{-4} \mathrm{M}$, did not influence the acetylcholine output elicited by preganglionic stimulation of canine stellate ganglion. 


\subsection{Effects of the NO Scavenger Carboxy-PTIO on $\alpha, \beta$-meATP-Induced Reduction of Acetylcholine Release}

Carboxy-PTIO is a stable compound and a scavenger of NO radicals that is widely used to remove endogenous NO [33]. As shown in Figure 6, the $\alpha, \beta$-meATP-induced inhibition of acetylcholine release during preganglionic stellate stimulation was antagonized by incubation with $10^{-5} \mathrm{M}$ carboxy-PTIO. Carboxy-PTIO, alone, at the same concentration, did not affect the acetylcholine release elicited by preganglionic stimulation (Figure 6). ATP-stimulated NO production in carotid body efferent glossopharyngeal neurons is inhibited by carboxy-PTIO at a concentration of $10^{-4} \mathrm{M}[34]$.

\subsection{Effects of $\alpha, \beta$-meATP on $\mathrm{NO}_{\mathrm{x}}^{-}$Levels, and Antagonism by $\mathrm{P} 2 \mathrm{X}_{1}, \mathrm{P}_{2} \mathrm{X}_{3}$, and $\mathrm{P} 2 \mathrm{X}_{2 / 3}$ Receptor Antagonist TNP-ATP and nNOS Inhibitor 3-Bromo-7-nitroindazole}

As shown in Figure 7 and Figure 8, the $\alpha, \beta$-meATP-induced increase in $\mathrm{NO}_{x}^{-}$levels was antagonized by the nNOS inhibitor 3-bromo-7-nitroindazole at $10^{-5} \mathrm{M}$ and by the $\mathrm{P} 2 \mathrm{X}_{1}, \mathrm{P}_{2} \mathrm{X}_{3}$, and $\mathrm{P} 2 \mathrm{X}_{2 / 3}$ antagonist TNP-ATP at $10^{-7} \mathrm{M}$. These agents alone, at the same concentrations did not affect the basal $\mathrm{NO}_{x}^{-}$levels in the absence of $\alpha, \beta$-meATP. As we reported in an earlier study [20], endothelin-induced NO production by canine stellate ganglia was completely antagonized by 3-bromo-7-nitroindazole at the same concentration.

\section{Discussion}

In this study, we investigated the contribution of the specific ATP receptor subtype and the NO system to the presynaptic inhibition of canine stellate ganglionic nerve transmission induced by ATP agonists. Previous experiments using acetylcholine assays demonstrated that there were no changes in the release of acetylcholine elicited by eight successive preganglionic stimulations at 10-min intervals [17] [18]. Under the same experimental conditions, the output of acetylcholine elicited by preganglionic stimulation was modulated by exposure of the isolated stellate ganglia to ATP analogs $\left(\alpha, \beta\right.$-meATP, $\beta, \gamma$-meATP and 2MeSATP) at concentrations between $10^{-7}$ and $10^{-4} \mathrm{M}$.

Abbracchio and Burnstock [35] described "P2X-" and "P2Y-purinoceptors" with distinct pharmacological profiles and tissue distributions. The P2X-receptor was most potently activated by stable analogs of ATP, such as $\alpha, \beta$-meATP and $\beta, \gamma$-meATP, whereas for the P2Y receptor, 2MeSATP was the most potent agonist and

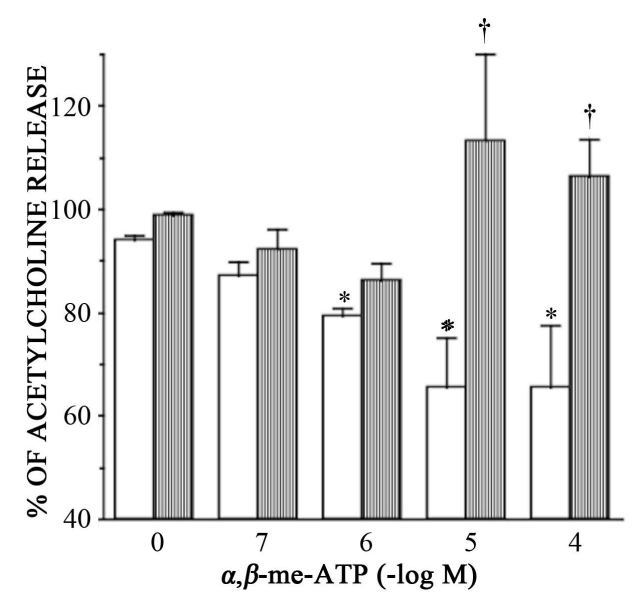

Figure 6. Effect of the NO scavenger carboxy-PTIO, on the $\alpha, \beta$-methylene-ATP-induced reduction in acetylcholine output elicited by preganglionic stimulation in untreated $(\square)$ and $10^{-5} \mathrm{M}$ carboxy-PTIO-treated ( the mean basal amount of acetylcholine released by preganglionic stimulation before drug addition were $6.7 \pm 1.05$ and $5.0 \pm 0.48 \mathrm{nmol} / 10 \mathrm{~min} / \mathrm{g}$. *significant difference between the values before and after $\alpha, \beta$-methylene-ATP in the same ganglion $(\mathrm{p}<$ $0.05)$. † significant difference between untreated and carboxy-PTIO-treated ganglia ( $\mathrm{p}<$ 0.05 ). Each column represents the mean of 5 ganglia. See the legends to Figure 2 for additional explanation. 


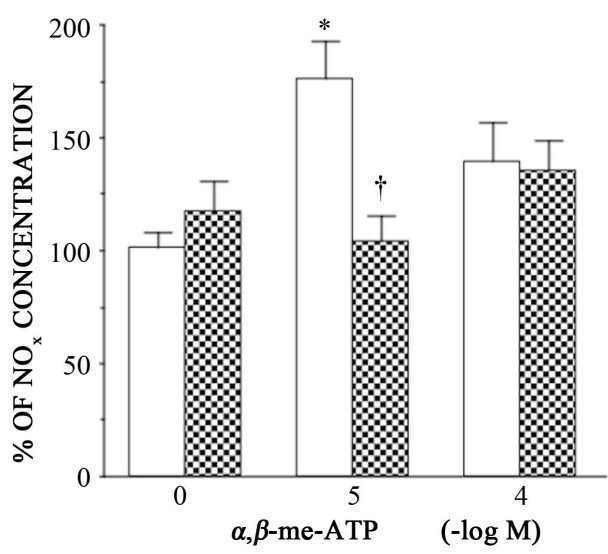

Figure 7. Effect of the $\mathrm{P} 2 \mathrm{X}_{1}$ and $\mathrm{P} 2 \mathrm{X}_{3}$ receptor antagonist, TNP-ATP, on the $\alpha, \beta$ methylene-ATP-induced increase in $\mathrm{NO}$ metabolites $\left(\mathrm{NO}_{2}^{-}+\mathrm{NO}_{3}^{-}, \mathrm{NO}_{\mathrm{x}}\right)$ output in untreated $\left(\square\right.$ ) and $10^{-7} \mathrm{M}$ TNP-ATP-treated ( $\mathbf{\square}$ ) ganglia. In two groups of ganglia, the mean basal amount of $\mathrm{NO}_{\mathrm{x}}$ released before drug addition was $179 \pm 78.70$ and $183.5 \pm 73.05 \mathrm{pmol} / 20 \mathrm{ml} / 30 \mathrm{~min} / \mathrm{g}$. *significant difference between the values before and after $\alpha, \beta$-methylene-ATP addition in the same ganglion $(\mathrm{p}<0.05)$. $\uparrow$ significant difference between untreated and TNP-ATP-treated ganglia $(\mathrm{p}<0.05)$. Each column represents the mean of 5 ganglia. See the legends to Figure 2 for additional explanation.

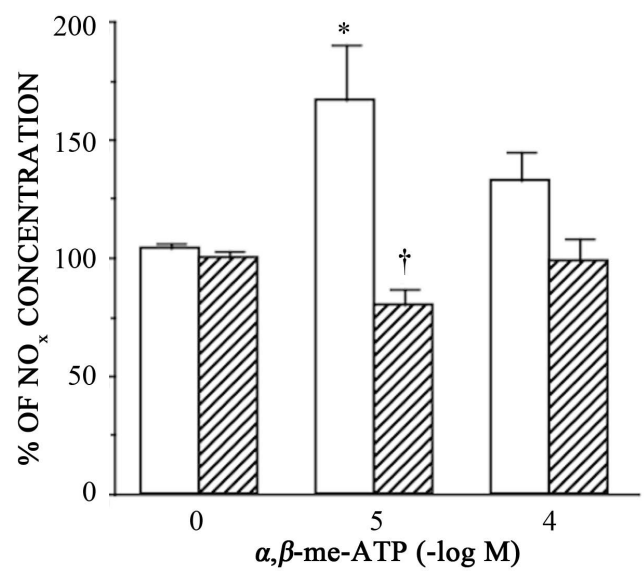

Figure 8. Effect of the nNOS inhibitor, 3-bromo-7-nitroindazole on the $\alpha, \beta$-methylene-ATP-induced increase in $\mathrm{NO}$ metabolites $\left(\mathrm{NO}_{2}^{-}+\mathrm{NO}_{3}^{-}, \mathrm{NOx}\right)$ output in untreated $(\square)$ and $10^{-5} \mathrm{M}$ 3-bromo-7-nitroindazole-treated ( $\mathbb{Z}$ ) ganglia. In two groups of ganglia, the mean basal amounts of $\mathrm{NO}_{\mathrm{x}}$ released before drug additions were 341.5 \pm 77.84 and $360.3 \pm 82.39 \mathrm{pmol} / 20 \mathrm{ml} / 30 \mathrm{~min} / \mathrm{g}$. *significant difference between the values before and after $\alpha, \beta$-methylene-ATP in the same ganglion $(\mathrm{p}<0.05)$. $\uparrow$ significant difference between untreated and 3-bromo-7-nitroindazole-treated ganglia $(\mathrm{p}<0.05)$. Each column represents the mean of 5 ganglia. See the legends to Figure 2 for additional explanation.

$\alpha, \beta$-meATP and $\beta, \gamma$-meATP were weak or inactive as agonists. In the experiments described here, preincubation with $\alpha, \beta$-meATP reduced the acetylcholine release elicited by preganglionic stimulation in a concentration-dependent manner, whereas the same concentrations of $\beta, \gamma$-meATP augmented acetylcholine release. The discrepancy between these responses to $\mathrm{P} 2 \mathrm{X}$ agonists remains to be explained.

In our experiments, the reduction in acetylcholine release elicited by $\alpha, \beta$-meATP was completely antagonized by pretreatment with the nonselective $\mathrm{P} 2$ receptor antagonist PPADS and by the $\mathrm{P} 2 \mathrm{X}_{1}, \mathrm{P} 2 \mathrm{X}_{3}$ and $\mathrm{P} 2 \mathrm{X}_{2 / 3}$ antagonist, TNP-ATP. In contrast, in primary cultures of rat superior cervical ganglion neurons, a P2Y agonist, 2MeSATP, and a selective $\mathrm{P}_{2} \mathrm{Y}_{1}$ agonist, MRS2365, significantly enhance the stimulation-induced $\left[{ }^{3} \mathrm{H}\right]$-nore- 
pinephrine overflow from ganglion neurons treated with pertussis toxin, and this effect was abolished by the

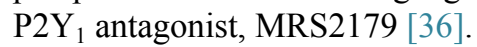

In our experiment, 2MeSATP tended to enhance the preganglionic stimulation-evoked acetylcholine release, although the differences were not significant. Although 2MeSATP has been widely regarded as a selective P2Y receptor agonist, it also acts as a potent agonist of P2X receptors [6]. Therefore, we have assumed that the nonsignificant, small increase in acetylcholine output induced by preganglionic stimulation in the presence of 2MeSATP is likely to represent the average effect of 2MeSATP on P2X and P2Y receptors. It is possible that the activation of presynaptic $\mathrm{P} 2 \mathrm{Y}$ receptors is capable of facilitating neurotransmitter release from preganglionic neurons. On the other hand, incubation with the P2X receptor agonist $\beta, \gamma$-meATP induced an increment rather than an inhibition of acetylcholine release elicited by preganglionic stimulation of canine stellate ganglia. These changes in acetylcholine release induced by the P2X agonist $\beta, \gamma$-meATP and the P2X and P2Y ligand 2MeSATP will require further research.

In sympathetic and parasympathetic ganglia, $\mathrm{P} 2 \mathrm{X}$ receptor subtypes are expressed in both presynaptic and postsynaptic compartments; their role in fast transmission is modulatory, largely through the regulation of neurotransmitter release [2]. The evidence for the involvement of P2 receptors in the inhibition of acetylcholine release has been obtained in the frog neuromuscular junction [37], rat submandibular ganglia [31], and the rabbit retina [38]. ATP activates a presynaptic $\mathrm{P} 2$ receptor to inhibit acetylcholine release from preganglionic nerves in the submandibular ganglia. The inhibitory effects of ATP on nerve-evoked transmitter release are antagonized by bath application of PPADS or suramin, suggesting that ATP activates a presynaptic P2 receptor to inhibit acetylcholine release from preganglionic nerves in the submandibular ganglia [31].

However, the specific receptor subtype involved in the $\alpha, \beta$-meATP-induced inhibition of sympathetic neurotransmission has not yet been determined. In our experiments, the ATP analog $\alpha, \beta$-meATP inhibited sympathetic ganglionic transmission by reducing the acetylcholine release at preganglionic terminals. Furthermore, both the nonspecific P2 receptor antagonist PPADS and the P2X-specific receptor antagonist TNP-ATP, which is a potent antagonist selective for $\mathrm{P} 2 \mathrm{X}_{1}, \mathrm{P} 2 \mathrm{X}_{3}$ and heteromeric $\mathrm{P} 2 \mathrm{X}_{2 / 3}$ receptors [39], completely antagonized the $\alpha, \beta$-meATP-induced inhibition of acetylcholine release elicited by preganglionic stellate stimulation. Taken together, these results indicate that the presynaptic inhibition of acetylcholine output induced by $\alpha, \beta$-meATP is mediated by activation of the $\mathrm{P} 2 \mathrm{X}$ receptors in the canine presynaptic stellate ganglion.

NOS is widely distributed in the preganglionic sympathetic neurons of rat pre- and paravertebral [23] [40] and superior cervical [24] ganglia. In contrast, NOS is localized to a population of sympathetic postganglionic neurons in the guinea pig paravertebral and inferior mesenteric ganglia [25] and in the cat stellate and lower lumbar ganglia [27]. Furthermore, both neuronal NOS (nNOS) and endothelial NOS (eNOS) are naturally present in neuronal tissue [41].

These findings indicate that nNOS is present in pre and/or postganglionic sympathetic neurons. On the other hand, NO plays an important role in the control of synaptic function in both the peripheral and central nervous system [21]. In a previous report, we showed that the NO donor S-nitroso-N-acetylpenicillamine reduced the acetylcholine release elicited by preganglionic stellate stimulation in dogs, in a dose-dependent manner [20]. ATP acts as a paracrine factor in the thick ascending limb of Henle's loop, inducing NO production via activation of P2X receptors [42]. In a recent study, Yukawa et al. [43] showed that extracellular ATP induces NO production in cochlear spiral ganglion neurons, but that this was abolished in the presence of L-NAME. Furthermore, ATP and the P2X agonist $\alpha, \beta$-meATP mimicked the effects of ATP to stimulate a rise in $\left[\mathrm{Ca}^{2+}\right]$, leading to nNOS activation and NO production in isolated neurons of the glossopharyngeal nerve; this NO signal was inhibited by the purinergic blocker suramin, the NO inhibitor L-NAME, and the NO scavenger carboxy-PTIO [34]. Several studies suggest that P2X receptor activation leads to an increased NO production, proposing a functional link between ATP and NO production [44]. In this study on the sympathetic ganglion, the preganglionic inhibition by $\alpha, \beta$-meATP of the acetylcholine output elicited by preganglionic stimulation was also inhibited by treatment with 3-bromo-7-nitroindazole, a selective nNOS inhibitor and carboxy-PTIO, a NO scavenger.

On the other hand, exposure to the ATP analog $\alpha, \beta$-meATP at a dose of $10^{-5} \mathrm{M}$ increased the levels of total NO metabolites in the incubation medium, an increase that disappeared after the addition of TNP-ATP or 3-bromo-7-nitroindazole. In contrast, a high dose of $\alpha, \beta$-meATP $\left(10^{-4} \mathrm{M}\right)$, which reduced acetylcholine release, did not significantly increase NO production (Figure 7 and Figure 8). The mechanism of NO production elicited by P2X7 receptor activation may be involved in regulation of neuronal excitability [44]. This discrepancy 
between the inhibition of acetylcholine and NO production at the high dose of $\alpha, \beta$-meATP possibly could be involved in the distinction between the presence or absence of electrical stimulation. However, the mechanisms underlying the discrepancy remain to be determined. These results suggest that the increase in NO formation mediated by the activation of $\mathrm{P} 2 \mathrm{X}$ receptors may have a role in the $\alpha, \beta$-meATP-induced preganglionic inhibition of acetylcholine release in the canine stellate ganglion.

Endogenous NO has been shown in many tissues to affect soluble guanylyl cyclase [45] [46] and to bind tightly to the heme region of this cyclase; it causes an increase in cGMP levels, which affects ion channels [47]. ODQ has previously been shown to abolish the elevation of cGMP accumulation induced by nitoprusside in rat superior cervical ganglia [48]. In our previous investigation using 8-bromo-cGMP, a membrane-permeable cGMP analog, we found a dose-dependent decrease in acetylcholine release elicited by preganglionic stimulation [20]. In the experiments described here, the inhibition by $\alpha, \beta$-meATP of acetylcholine release elicited by preganglionic stellate stimulation was antagonized by treatment with ODQ, a selective inhibitor of soluble guanylyl cyclase. These results suggest that $\alpha, \beta$-meATP stimulates the receptor-mediated formation of NO metabolites activating soluble guanylyl cyclase, and thus leads to increased cGMP content in the canine stellate ganglia.

\section{Conclusion}

In conclusion, $\alpha, \beta$-meATP inhibits sympathetic ganglionic transmission at presynaptic sites via purinergic $\mathrm{P} 2 \mathrm{X}$ receptors by reducing the output of acetylcholine release through, at least in part, the stimulation of NO production and cGMP pathways.

\section{Acknowledgements}

The authors are grateful to Dr. Takeshi Katsuragi PhD and Dr. Tatsuo Furukawa MD PhD (Department of Pharmacology, School of Medicin, Fukuoka University, Japan) for valuable advice, Dr William Waggott D. Phil. (Oxfordword Managing Director) for critical reading of the manuscript.

\section{Funding}

This study was supported in part by a Grant-in-Aid for Scientific Research (03670113) from the Ministry of Education, Science and Culture and fund for scientific research from Fukuoka University in Japan.

\section{Current Affiliation}

Medical Informatics and Research Unit, Faculty of Pharmaceutical Sciences (K.K.) and Department of Biochemistry, Faculty of Medicine, (H.Y.), Fukuoka University.

\section{References}

[1] Feldberg, W. and Hebb, C. (1948) The Stimulating Action of Phosphate Compounds on the Perfused Superior Cervical Ganglion of the Cat. The Journal of Physiology, 107, 210-221. http://dx.doi.org/10.1113/jphysiol.1948.sp004264

[2] Burnstock, G. (2007) Physiology and Pathophysiology of Purinergic Neurotransmission. Physiological Reviews, 87, 659-797. http://dx.doi.org/10.1152/physrev.00043.2006

[3] Burnstock, G. and Kennedy, C. (1985) Is There a Basis for Distinguishing Two Types of P2-Purinoceptor? General Pharmacology, 16, 433-440. http://dx.doi.org/10.1016/0306-3623(85)90001-1

[4] Akasu, T, Hirai, K. and Koketsu, K. (1982) Moduratory Effect of ATP on the Release of Acetylcholine from Presynaptic Nerve Terminals in Bullfrog Sympathetic Ganglia. The Kurume Medical Journal, 29, 75-83. http://dx.doi.org/10.2739/kurumemedj.29.75

[5] Dunn, P.M., Zhong, Y. and Burnstock, G. (2001) P2X Receptors in Peripheral Neurons. Progress in Neurobiology, 65, 107-134. http://dx.doi.org/10.1016/S0301-0082(01)00005-3

[6] Ralevic, V. and Bernstock, G. (1998) Receptors for Purines and Pyrimidines. Pharmacological Reviews, 50, 413-492.

[7] Bean, B.P., Williams, C.A. and Ceelen, P.W. (1990) ATP-Activated Channels in Rat and Bullfrog Sensory Neurons: Current-Voltage Relation and Single-Channel Behavior. The Journal of Neuroscience, 10, 11-19.

[8] Krishtal, O.A., Marchenko, S.M. and Pidoplichko, V.I. (1983) Receptor for ATP in the Membrane of Mammalian Sensory Sensory Neurons. Neuroscience Letters, 31, 41-45. http://dx.doi.org/10.1016/0304-3940(83)90524-4 
[9] Khakh, B.S., Humphry, P.P.A. and Surprenant. A. (1995) Electrophysiological Properties of P2X-Purinoceptors in Rat Superior Cervical, Nodose and Guinea-Pig Coeliac Neurons. The Journal of Neuroscience, 484, 385-395. http://dx.doi.org/10.1113/jphysiol.1995.sp020672

[10] Connolly, G.P., Harrison, P.J. and Stone, T.W. (1993) Action of Purine and Pyrimidine Nucleotides on the Rat Superior Cervical Ganglion. British Journal of Pharmacology, 110, 1297-1304. http://dx.doi.org/10.1111/j.1476-5381.1993.tb13959.x

[11] Reekie, F.M. and Burnstock, G. (1994) Some Effects of Purinse on Neurons of Guinea-Pig Superior Cervical Ganglia. General Pharmacology, 25, 143-148. http://dx.doi.org/10.1016/0306-3623(94)90024-8

[12] Evans, R.J., Derkach, V. and Surprenant, A. (1992) ATP Mediates Fast Synaptic Transmission in Mammalian Neurones. Nature, 36, 503-505. http://dx.doi.org/10.1038/357503a0

[13] Sillinsky, E.M., Gerzanich, V. and Vanner, S.M. (1992) ATP Medistes Excitatory Synaptic Transmission in Mammalian Neurones. British Journal of Pharmacology, 106, 762-763. http://dx.doi.org/10.1111/j.1476-5381.1992.tb14408.x

[14] Zhong, Y., Dunn, P.M. and Burnstock, G. (2000) Guinea-Pig Sympathetic Neurons Express Varying Proportions of Two Distinct P2X Receptors. Journal of Physiology, 523, 391-402. http://dx.doi.org/10.1111/j.1469-7793.2000.t01-1-00391.x

[15] Cloues, R., Jones, S. and Brown, D.A. (1993) $\mathrm{Zn}^{2+}$ Potentiates ATP-Activated Currents in Rat Sympathetic Neurons. Pflügers Archiv European Journal of Physiology, 424, 152-158. http://dx.doi.org/10.1007/BF00374606

[16] Zhong, Y., Dunn, P.M. and Burnstock, G. (2000) Pharmacological Comparison of P2X Receptors on Rat Coeliac, Mouse Coeliac and Mouse Pelivic Ganglion Neurons. Neuropharmacology, 39, 172-180. http://dx.doi.org/10.1016/S0028-3908(99)00145-8

[17] Ohjimi, H., Kushiku, K., Yamada, H., Kuwahara, T., Kohno, Y. and Furukawa, T. (1994) Increase of Acetylcholine release by Nebracetam in Dog Cardiac Sympathetic Ganglion. Journal of Pharmacology and Experimental Therapeutics, 268, 396-402.

[18] Kushiku, K., Ohjimi, H., Yamada, H., Kuwahara, T. and Furukawa, T. (1995) Activation of Endogenous Thromboxane $\mathrm{A}_{2}$ Biosynthesis Mediates Presynaptic Inhibition by Endothelin-3 of Dog Stellate Ganglionic Transmission. Journal of Pharmacology and Experimental Therapeutics, 272, 70-76.

[19] Mukai, M., Kushiku, K., Yamada, H., Ymada, K., Dan, K. and Furukawa, T. (1996) The Inhibition of Ganglionic Transmission via Presynaptic Dopamine $\mathrm{DA}_{1}$ and Postsynaptic $\mathrm{DA}_{2}$ Receptor Activation in the Canine Cardiac Sympathetic Ganglia. Journal of Pharmacology and Experimental Therapeutics, 279, 822-829.

[20] Yamada, K., Kushiku, K., Yamada, H., Katsuragi, T., Furukawa, T., Noguchi, H. and Ono, N. (1999) Contribution of Nitric Oxide to the Presynaptic Inhibition by Endothelin $\mathrm{ET}_{\mathrm{B}}$ Receptor of the Canine Stellate Ganglionic Transmission. Journal of Pharmacology and Experimental Therapeutics, 290, 1175-1181.

[21] Schuman, E.M. and Madison, D.V. (1994) Nitric Oxide and Synaptic Function. Annual Review of Neuroscience, 17, 153-183. http://dx.doi.org/10.1146/annurev.ne.17.030194.001101

[22] Bredt, D.S., Ferris, C.D. and Snyder, S.H. (1992) Nitric Oxide Synthase Regulatory Sites: Phosphorylation by Cyclic AMP-Dependent Protein Kinase, Protein Kinase C and Calcium/Calmodulin Kinase; Identification of Flavin and Calmodulin Binding Sites. Journal of Biological Chemistry, 267, 10976-10981.

[23] Anderson, C.R., Edwards, S.L., Furness, J.B., Bredt, D.S. and Snyder, S.H. (1993) The Distribution of Nitric Oxide Synthase-Containing Autonomic Preganglionic Terminals in the Rat. Brain Research, 614, 78-85. http://dx.doi.org/10.1016/0006-8993(93)91020-S

[24] Okamura, H., Umehara, K., Tadaki, N., Hisa, Y., Esumi, H. and Ibata, Y. (1995) Sympathetic Preganglionic Neurons Contain Nitric Oxide Synthase and Project to the Superior Cervical Ganglion: Combind Application of Retrograde Neuronal Tracer and NADPH-Diaphorase Histochemistry. Brain Research Bulletin, 36, 491-494. http://dx.doi.org/10.1016/0361-9230(94)00234-R

[25] Höhler, B., Olry, R., Mayer, B. and Kummer, W. (1995) Nitric Oxide Synthase in Guiner Pig Sympathetic Ganglia: Correlation with Tyrosine Hydroxylase and Neuropeptides. Histochemistry and Cell Biology, 104, 21-28.

[26] Dun, N.J., Dun, S.L., Wu, S.Y., Förstermann, U., Schmidt, H.H. and Tseng, L.F. (1993) Nitric Oxide Synthase Immunoreactivity in the Rat, Mouse, Cat and Aquirrel Monkey Spinal Cord. Neuroscience, 54, 845-857. http://dx.doi.org/10.1016/0306-4522(93)90579-5

[27] Anderson, C.R., McAllen, R.M. and Edwards, S.L. (1995) Nitric Oxide Synthase and Chemical Coding in Cat Sympathetic Postganglionic Neurons. Neuroscience, 68, 255-264. http://dx.doi.org/10.1016/0306-4522(95)00143-7

[28] Belai, A. and Burnstock, G. (1994) Evidence for Coexistence of ATP and Nitric Oxide in Non-Adrenergic, NonCholinergic (NANC) Inhibitory Neurons in the Rat Ileum, Colon and Anococcygeus Muscle. Cell and Tissue Research, 278, 197-200. http://dx.doi.org/10.1007/BF00305792 
[29] Eva, C., Hadjiconstantinou, M., Neff, N.H. and Meek, J.L. (1984) Acetylcholine Measurement by High-Performance Liquid Chromatography Using an Enzyme-Loaded Post-Column Reator. Analytical Biochemistry, 143, 320-324. http://dx.doi.org/10.1016/0003-2697(84)90670-5

[30] Potter, P.E., Meek, J.L. and Neff, N.H. (1983) Acertylcholine and Choline in Neuronal Tissue Measured by HPLC with Electrochemical Detection. Journal of Neurochemistry, 41, 188-194. http://dx.doi.org/10.1111/j.1471-4159.1983.tb13668.x

[31] Smith, A.B., Hansen, M.A., Liu, D.M. and Adams, D.J. (2001) Pre- and Postsynaptic Actions of ATP on Neurotransmission in Rat Submandibular Ganglia. Neuroscience, 107, 283-291. http://dx.doi.org/10.1016/S0306-4522(01)00347-5

[32] Connolly, G.P. (1995) Differentiation by Pyridoxal 5-Phosphate, PPADS and isoPPADS between Responses Mediated by UTP and Those Evoked by Methylene-ATP on Rat Sympathetic Ganglia. British Journal of Pharmacology, 114, 727-731. http://dx.doi.org/10.1111/j.1476-5381.1995.tb17199.x

[33] Maeda, H., Akaike, T., Yoshida, M. and Suga, M. (1994) Multiple Functions of Nitric Oxide in Pathophysiology and Microbiology: Analysis by New Nitric Oxide Scavenger. Journal of Leukocyte Biology, 56, 588-592.

[34] Lowe, M., Park, S.J., Nurse, C.A. and Campanucci, V.A. (2013) Purinergic Stimulation of Carotid Body Efferent Glossopharyngeal Neurones Increases Intracellular $\mathrm{Ca}^{2+}$ and Nitric Oxide Production. Experimental Physiology, 98, 1199-1212. http://dx.doi.org/10.1113/expphysiol.2013.072058

[35] Abbracchio, M.P. and Burnstock, G. (1994) Purinoceptors: Are There Families of P2x and P2y Purinoceptors? Pharmacology \& Therapeutics, 64, 445-475. http://dx.doi.org/10.1016/0163-7258(94)00048-4

[36] Chandaka, G.K., Salzer, I., Drobny, H., Boehm, S. and Schicker, K.W. (2011) Facilitation of Transmitter Release from Rat Sympathetic Neurons via Presynaptic P2Y1 Receptors. British Journal of Pharmacology, 164, 1522-1533. http://dx.doi.org/10.1111/j.1476-5381.2011.01466.x

[37] Giniatullin, R.A. and Sokolova, E.M. (1998) ATP and Adenosine Inhibit Transmitter Release at the Frog Neuromuscular Junction through Distinct Presynaptic Receptors. British Journal of Pharmacology, 124, 839-844. http://dx.doi.org/10.1038/sj.bjp.0701881

[38] Neal, M. and Cunningham, J. (1994) Modulation of Endogenous ATP of the Light-Evoked Release of Ach from Retinal Cholinergic Neurones. British Journal of Pharmacology, 113, 1085-1087. http://dx.doi.org/10.1111/j.1476-5381.1994.tb17106.x

[39] Virginino, C., Robertson, G., Surprenant, A. and North, R.A. (1998) Trinitrophenyl-Substituted Nucleotides Are Potent Antagonists Selective for $\mathrm{P}_{2} \mathrm{X}_{1}, \mathrm{P}_{2} \mathrm{X}_{3}$ and Heteromeric $\mathrm{P} 2 \mathrm{X}_{2 / 3}$ Receptors. Molecular Pharmacology, 53, 969-973.

[40] Blottner, D. and Bumgarten, H.-G. (1992) Nitric Oxide Synthetase (NO)-Containing Sympathoadrenal Cholinergic Neurons of the Rat IML-Cell Column: Evidence from Histochemistry, Immunohistochemistry and Retrograde Labeling. Journal of Comparative Neurology, 316, 45-55. http://dx.doi.org/10.1002/cne.903160105

[41] Dinerman, J.L., Dawson, T.M., Schell, M.J., Snowman, A. and Snyder, S.H. (1994) Endothelial Nitric Oxide Synthase Localized to Hippocampal Pyramidal Cells: Implication for Synaptic Plasticity. Proceedings of the National Academy of Sciences of the United States of America, 91, 4214-4218. http://dx.doi.org/10.1073/pnas.91.10.4214

[42] Silva, G., Beierwaltes, W.H. and Garvin, J.L. (2006) Extracellular ATP Stimulates NO Production in Rat Thick Ascending Limb. Hypertension, 47, 563-567. http://dx.doi.org/10.1161/01.HYP.0000197954.93874.ef

[43] Yukawa, H., Shen, J., Harada, N., Cho-Tamaoka, H. and Yamashita, T. (2005) Acute Effects of Glucocorticoids on ATP-Induced $\mathrm{Ca}^{2+}$ Mobilization and Nitric Oxide Production in Cochlear Spiral Ganglion Neurons. Neuroscience, 130, 485-496. http://dx.doi.org/10.1016/j.neuroscience.2004.09.037

[44] Codocedo, J.F., Godoy, J.A., Poblete, M.I., Inestrosa, N.C. and Huidobro-Toro, J.P. (2013) ATP Induces NO Production in Hippocampal Neurons by P2X7 Receptor Activation Independent of Glutamate Signaling. PloS ONE, 8, e57626. http://dx.doi.org/10.1371/journal.pone.0057626

[45] Arnold, W.P., Mittal, C.K., Katsuki, S. and Murad, F. (1977) Nitric Oxide Activates Guanylate Cyclase and Increases Guanosine 3',5'-Cyclic Monophosphate Levels in Various Tissue Preparations. Proceedings of the National Academy of Sciences of the United States of America, 74, 3203-3207. http://dx.doi.org/10.1073/pnas.74.8.3203

[46] Murad, F., Mittal, C.K., Arnold, W.P., Katsuki, S. and Kimura, H. (1978) Guanylate Cyclase: Activation by Azide, Nitro Compounds, Nitric Oxide and Hydroxyl Radical and Inhibition by Hemoglobin and Myoglobin. Advances in Cyclic Nucleotide Research, 9, 145-158.

[47] Rascon, A., Lindgren, S., Stavenow, L., Belfrage, P., Andersson, K-E., Manganiello, V.C. and Degarman, E. (1992) Purification and Properties of the cGMP-Inhibited cAMP Phosphodiesterase from Bovine Aortic Smooth Muscle. Biochimica et Biophysica Acta, 1134, 149-156. http://dx.doi.org/10.1016/0167-4889(92)90038-D

[48] Southam, E., Charles, S.L. and Garthwaite, J. (1996) The Nitric Oxide-Cyclic GMP Pathway and Synaptic Plasticity in the Rat Superior Cervical Ganglion. British Journal of Pharmacology, 119, 527-532.

http://dx.doi.org/10.1111/j.1476-5381.1996.tb15703.x 


\section{Abbreviations}

2MeSATP, 2-methyl-thio-ATP; $\alpha, \beta$-meATP, $\alpha, \beta$-methylene-ATP; $\beta, \gamma$-meATP, $\beta, \gamma$-methylene-ATP; carboxyPTIO, 2-(4-carboxyphenyl)-4,4,5,5-tetramethylimidazoline-1-oxyl-3-oxide; HPLC, high performance liquid chromatography; L-NAME, $\mathrm{N}^{\mathrm{G}}$-nitro-L-arginine methyl ester; NOS, nitric oxide synthase; ODQ, 1H-[1,2,4]-oxadiazolo[4,3-a]quinoxalin-1-one; PPADS, pyridoxalphosphate-6-azophenyl-2',4'-disulphonic acid; TNP-ATP, 2',3'O-(2,4,6-trinitrophenyl)-adenosine 5'-triphosphate. 